\title{
Planes militares de Adenauer en España. \\ El proyecto de instalación de bases militares de 1960
}

\author{
Carlos Collado Seidel
}

\section{SITUACIÓN Y RUMORES}

La ayuda militar del III Reich a Franco durante la guerra civil española mediante el envio de la Legión Cóndor, asi como la intervención de la División Azul en el frente de Rusia durante la Segunda Guerra Mundial, determinaron fuertemente la imagen de las relaciones entre España y Alemania mientras persistió en España el régimen franquista. Por esto, en tanto que otras naciones como los Estados Unidos volvían a establecer contactos políticos y militares con una España que seguía siendo considerada como fascista ', la República Federal de Alemania, cargada con la herencia del pasado tuvo que actuar siempre muy cautelosamente con respecto a este país para no despertar penosos recuerdos o incluso levantar olas de indignación.

No obstante esto, al finalizar la Segunda Guerra Mundial, y aun partiendo de situaciones políticas diametralmente opuestas, no se dio una interrupción decidida de relaciones entre ambos paises. Los tradicionales lazos de amistad encontraron su continuación en la nueva clase política

1 "El último reducto del fascismo" como lo formula Florentino Portero en PORTERO, Florentino, Franco aislado. La cuestión española (1945-1950). Madrid 1989, pág. 27. 
de la recién creada República Federal con frecuentes alusiones a la breve historia común. A nivel personal se mantuvieron estrechas relaciones entre los dirigentes de los partidos cristiano-demócratas, de tendencia fuertemente conservadora bajo el canciller Konrad Adenauer, y destacados políticos españoles. Entre el tradicionalismo conservador y católico del régimen de Franco y los principios de la Unión Cristiano-Demócrata, partido largos años en el poder durante la era de Adenauer, se daban muchos puntos de contacto exentos de toda discrepancia.

Sin embargo, la reanudación de las relaciones diplomáticas hacia escasos progresos. Cuando en noviembre de 1950 quedó sin efecto la resolución de la ONU de 1946 por la cual se recomendaba la suspensión de relaciones diplomáticas con España a consecuencia de la cual España había quedado políticamente aislada ${ }^{2}$, el Gobierno español nombró embajador en Bonn, en mayo de 1951, a Antonio Maria Aguirre y Gonzalo, diplomático de carrera y jefe de la Misión española ante la Alta Comisión aliada. Pasó sin embargo aún más de un año hasta que Adenauer se decidiera por su parte a nombrar embajador alemán en Madrid. El nombramiento del principe Adalberto de Baviera, gran amigo de España y a quien unian lazos de parentesco con la familia real española, fue una hábil decisión política por parte de Adenauer, pues por un lado el nombramiento del príncipe fue acogido con gran satisfacción en España (ya en 1929 había sido nombrado delegado de Turismo español en Alemania) ${ }^{3}$ y por otro la persona designada no resultaba para Adenauer riesgo alguno en el aspecto político. La avanzada edad del príncipe y la ausencia de ambiciones no hacian esperar de él gran actividad política; en tanto que, dada la distinción de su persona y su abolengo, era un buen augurio para la puesta en marcha de unas relaciones amistosas entre los dos países. Todo esto no podía despertar sospecha alguna al Consejo de los Aliados sobre los propósitos de Adenauer con respecto a Madrid. Pero aún después del restablecimiento de relaciones diplomáticas siguió siendo bastante difícil el acercamiento a alto nivel de los dos Gobiernos. Prueba de ello es el hecho de que ningún ministro de Asuntos Exteriores alemán viajara de forma oficial a Madrid hasta 1958, o que el mismo Adenauer nunca llegara a venir a España como canciller de la República Federal, por más que en varias ocasiones había estado prevista una visita de este género.

\footnotetext{
${ }^{2}$ Portero, op. cit., págs. 221 y sigs., y págs. 400 y sigs.

3 Archivo del Ministerio de Asuntos Exteriores (AMAE) Leg. R-510, Exp. 55. Asimismo fue el primer presidente de la Asociación hispano-alemana creada en Munich en octubre de 1950.
} 
Durante los últimos días de febrero y los primeros de marzo de 1960 un tema de inusitado interés acaparó la atención de toda la prensa internacional. Desde Moscú hasta la más pequeña República del Caribe se informaba sobre un posible acuerdo entre la República Federal de Alemania y España para la instalación de bases militares alemanas en territorio español. El asunto se discutió acaloradamente tanto en el parlamento alemán como en el británico, y también en el de algún otro país europeo, como el holandés. Se habló de un nuevo Eje Berlín-Madrid y se evocó una y otra vez la reciente historia alemana. Continuamente aparecían noticias según las cuales la República Federal pretendía instalar en España bases para el lanzamiento de misiles, evitando asi el control aliado. Empresas alemanas estuvieron bajo la sospecha de preparar la producción de armas atómicas en Bilbao ${ }^{4}$.

Pero estas noticias sensacionalistas de aquellos dias de febrero y marzo se disiparon rápidamente. La mayoría de esas acusaciones no pudieron mantenerse. Por otra parte, el comportamiento de Alemania respecto a los Aliados no pudo ser reprochado, habiendo quedado claro que tanto importantes cargos ejecutivos de la OTAN como los Gobiernos de los principales miembros de la Alianza habian estado informados sobre el proyecto y los pasos alemanes.

Estos sucesos, sin embargo, simbolizan claramente la problemática fundamental de las relaciones entre España y Alemania en la época de la posguerra, relaciones en que directa e indirectamente, pero de forma inconfundible, se reflejan la concepción y perspectiva politica de los respectivos Estados, así como las posibilidades y limitaciones de su política exterior en fuerza de los acontecimientos de la precedente contienda.

\section{MOTIVOS Y PREPARACIÓN DE LAS NEGOCIACIONES HISPANO- ALEMANAS}

La primera noticia sobre el proyecto de los alemanes de solicitar de España la concesión de ciertas facilidades logisticas para su ejército en la Península ibérica, la tuvo el ministro de Asuntos Exteriores el 8 de noviembre de 1959 , antevispera de su viaje oficial a Bonn ${ }^{5}$.

4 The Times, 3-3-1960 y 4-3-1960.

5 AMAE, Leg. R-8607, Exp. 6. Nota confidencial sobre la cuestión de las bases alemanas. $\mathrm{NCl}$, núm. $67 / 60$. 
¿Por qué pretende la República Federal de Alemania entablar conversaciones sobre un acuerdo militar tan repentinamente, al máximo nivel diplomático, y al parecer con prisas?

Las razones por las cuales la Alemania Occidental necesitaba bases en España fueron expuestas, hasta donde lo permitía el secreto militar, por fuentes oficiales alemanas, recalcando que se trataba principalmente de un problema de abastecimiento y refuerzos que afectaba al conjunto de la OTAN ${ }^{6}$.

En primer lugar dichas fuentes señalaron que la Alemania Occidental, en caso de guerra, tendria que depender de manera sustancial de los suministros procedentes del otro lado del Atlántico. Por otra parte, una guerra a base de proyectiles atómicos dirigidos, en el reducido territorio de la República Federal expuesto a toda clase de peligros, exigiria se tuvieran en cuenta las siguientes consideraciones.

1. Se produciría inevitablemente un retraso considerable antes de que los suministros comenzaran a llegar de América.

2. Una rápida transformación de la industria occidental dirigida a la producción de material bélico debía descartarse por imposible en los proyectos defensivos.

Consiguientemente, los depósitos de abastecimiento debian ser notablemente mayores que en las anteriores contiendas.

3. Por lo que se refiere a otros aspectos de indole militar, los depósitos habian de estar perfectamente diseminados, y habrian de evitarse las grandes concentraciones para hurtarse a la total destrucción atómica.

4. No sólo todos los puertos de Alemania Occidental, sino también el resto de los del Mar del Norte, serian con toda probabilidad inutilizables después de un ataque inicial soviético. Existia asimismo escasez de puertos para la distribución de material, que por otra parte también se necesitaría que fueran diseminados. Los puertos británicos sufririan un exceso de tráfico.

Aparte de estas declaraciones oficiales, existian también otros factores evidentes. Aunque se perseguia que las fuerzas de protección de la OTAN eran lo suficientemente fuertes para detener cualquier embestida repentina del Ejército Rojo, existía un claro peligro de que la mayor parte,

${ }^{6}$ Declaraciones oficiales publicadas por The Daily Telegraph, 1-3-1960. 
Planes militares de Adenauer en España. El proyecto de instalación ...

por no decir todo el territorio de la Alemania Occidental, se perdiera rápidamente ${ }^{7}$.

En dicho caso, los alemanes habrian de combatir en territorio francés, y caso de que continuase la retirada, podrian incluso, como otras unidades aliadas, encontrarse en España o muy próximos a ella. Aunque no se admitía, claramente se deducia la necesidad, por razones estratégicas, de buscar instalaciones de abastecimiento y sanitarias en España.

La capacidad que disponían en aquel momento los depósitos alemanes dejaba una gran laguna en lo referente a suministros, extremo que fue puesto de relieve en el seno de la OTAN y que se manifestó durante las maniobras "Side Step", llevadas a cabo en otoño de $1959^{8}$. Además de las necesidades del propio ejército, debian ser satisfechas en territorio alemán las de varios cientos de miles de soldados norteamericanos, ingleses, franceses y de otros paises, lo que crearía un considerable problema adicional para la Alemania Occidental.

Alemania ya venía efectuando negociaciones con Francia, así como con otros paises limitrofes, para la instalación de depósitos de abastecimiento; si bien por parte francesa no se habian ofrecido posibilidades adecuadas. El Gobierno francés había ofrecido la utilización de bases militares en Argelia, cosa que fue rechazada por el Gobierno alemán basándose en razones políticas ${ }^{9}$.

Aunque existía dentro de la OTAN una cierta integración en el aspecto de los abastecimientos, tal como en el uso de los oleoductos, las fuerzas de cada país integrante del pacto eran en gran medida responsables de su propio suministro. Consciente de la situación estratégica poco privilegiada de la Alemania Federal, y dada la carga que recaería sobre ella en caso de conflicto bélico, el Gobierno alemán pedía, basándose en el carácter internacional de las fuerzas de la OTAN, un sistema integrado de abastecimientos; si bien hasta aquel momento no había lle-

Estas consideraciones estratégicas desempeñaban ya una función importante durante las negociaciones sobre el acuerdo para la instalación de bases militares americanas de 1953. Véase VIÑAs, Ángel, Los pactos secretos de Franco con Estados Unidos. Bases, ayuda económica, recortes de soberania. Barcelona 1981, págs. 104 y sigs. Véase además Marquina Barrio, Antonio, España en la Política de Seguridad occidental (1939-1986). Madrid 1986, págs. 149 y ss., y 151 y ss.

${ }^{8}$ The Daily Telegraph, Art. cit.

${ }_{9}^{9}$ Carta del encargado de Negocios de la embajada de España en Bonn al ministro de Asuntos Exteriores en Madrid, 28-9-1960. AMAE, Leg. R-5854, Exp. 32. 
gado a alcanzar un apoyo significativo ${ }^{10}$. Bajo tales circunstancias, y teniendo en cuenta las necesidades de la OTAN en aquel momento, la opinión dominante en círculos gubernamentales alemanes era que no había otra salida que solicitar el apoyo de España.

El ministro de Asuntos Exteriores alemán, v. Brentano, planteó a su colega español, Fernando María Castiella y Maíz los propósitos alemanes durante una de las primeras conversaciones mantenidas con éste. Aparte de convenir guardar la máxima discreción sobre un asunto tan delicado, que por lo demás aún no se había comenzado a tratar, se consideró por ambas partes que era imprescindible proceder con total lealtad respecto a las potencias amigas a las que tanto Alemania como España estaban vinculadas ${ }^{11}$.

Por parte española estaba la existencia del Pacto Ibérico con Portugal y los acuerdos de 1953 con Estados Unidos, lo que obligaba a informar a los Gobiernos de Lisboa y Washington; y por parte alemana, dadas las estrechas relaciones entre Portugal y Gran Bretaña, así como la orientación política de la República Federal, se hacía imprescindible informar tanto a Washington como a Londres. Además de esto era necesario informar también a Francia. Este pais era la tercera potencia occidental vencedora de la Segunda Guerra Mundial, y precisamente por entonces tenía lugar una aproximación a París no sólo del Gobierno de Bonn, sino también por parte de Madrid ${ }^{12}$.

El primer paso dado por Alemania fue poner al Gobierno estadounidense al corriente de sus propósitos. Aprovechando la reunión de la OTAN celebrada en París en diciembre de 1959, la delegación alemana informó sobre sus intenciones de forma reservada al subsecretario de Estado para Asuntos de Europa, Livingstone T. Merchant ${ }^{13}$.

Todo esto sucedia antes de la visita del presidente de los Estados Unidos a Madrid los días 20 y 21 de diciembre. Pero durante la estancia de Eisenhower en la capital de España no se habló del asunto. El Go-

${ }^{10}$ Estas reclamaciones las venia haciendo la República Federal con periodicidad en el seno de la OTAN.

11 Documentos españoles afirman que el propósito de informar a las potencias estrechamente vinculadas se basaba en una actitud española a la que posteriormente se unió la parte alemana. Fuera como fuere, el Gobierno alemán no podria haberse permitido nunca el lujo de no informar a las potencias aliadas.

${ }_{12}$ La aproximación entre Franco y De Gaulle en 1959 tuvo un gran eco en la prensa y consolidó la posición internacional del régimen franquista.

${ }^{13}$ AMAE, Leg. R-8607, Exp. 6. Nota confidencial sobre la cuestión de las bases alemanas. $\mathrm{NCl}$, núm. $67 / 60$. 
Planes militares de Adenauer en España. El proyecto de instalación ...

bierno español, cauteloso, prefirió no tratarlo espontáneamente si no hacía alusión a ello el ilustre interlocutor norteamericano, considerando la cuestión aún demasiado inmadura ${ }^{14}$.

Más tarde se supo en Madrid - a través del embajador de la República Federal- que el Gobierno alemán había informado también de sus intenciones a Inglaterra, Francia e incluso al secretario general de la OTAN, Spaak, después de terminar la reunión de París. A mediados de enero, el ministro alemán de Defensa Strauß hizo un viaje a Portugal donde gestionó algunos acuerdos, poniendo en antecedentes al Gobierno lusitano de los proyectos alemanes en relación con España ${ }^{15}$. De esta manera quedaron informados todos los gobiernos implicados en el asunto de manera directa o indirecta.

Informados los Gobiernos aliados, el Gobierno federal, que al parecer tenía gran interés en seguir adelante con el proyecto, se propuso enviar a Madrid una comisión de sondeo, con atribuciones puramente técnicas, que debía estudiar si los planes de obtener facilidades logisticas en España eran viables, con objeto de iniciar después la auténtica negociación por vía diplomática ${ }^{16}$.

Paralelamente "algún otro país europeo" había iniciado contactos y exploraciones para establecer determinadas colaboraciones militares con España ${ }^{17}$. Precisamente esto dio lugar a una primera demora en la ejecución de los planes alemanes. El Gobierno de Bonn no quería que su primera gestión exploratoria coincidiese en Madrid con la de otro país ${ }^{18}$.

Poco después, tanto la embajada alemana en Madrid como la española en Bonn comunicaron al Ministerio de Asuntos Exteriores que el 16 de enero el Gobierno alemán había sido informado por el general Norstad y el secretario Spaak de la conveniencia de aplazar el viaje de la comisión, en razón del ambiente poco propicio a nivel internacional producido por la aparición de cruces gamadas e inscripciones antisemitas en distin-

14 Ibidem.

15 El Gobierno alemán confirmó estas gestiones durante una interpelación parlamentaria solicitada por el partido socialdemócrata el 6-4-1960. Deutscher Bundestag, 108. Sitzung. Bonn, den 6. April 1960, Große Anfrage der Fraktion der SPD betreffend deutsch-spanische Beziehungen, S. 5898.

16 AMAE, Leg. R-8607, Exp. 6. Nota confidencial NCl, núm. 67/60.

17 Efectivamente habian comenzado conversaciones entre España y Francia sobre una cooperación militar en el Norte de África. Estas conversaciones se intensificaron durante 1960.

18 AMAE, Leg. R-8607, Exp. 6. Nota confidencial NCl, núm. 67/60. 
tos lugares ${ }^{19}$. De la excitación surgida en torno a todo este asunto da prueba el siguiente texto:

«Spaak estaba visiblemente sorprendido de esta información, pareciéndole extremadamente desfavorable el momento actual en vista de la opinión mundial excitada por los incidentes antisemitas en Alemania.

Después de una prolongada discusión, desaconsejaba informar al Consejo en el momento actual, considerando suficiente una comunicación después de llegar a un acuerdo.

Los americanos nos han echo saber por la embajada de aqui, asi como por su representación en la OTAN, que desaconsejaban informar al Consejo ya en la hora actual. Evidentemente se reconocía en Washington unos problemas más graves en otros países aliados, y por esta razón se desearía remitir la consulta al Consejo de la OTAN hasta haber obtenido más claridad sobre las posibles consecuencias" ${ }^{20}$.

Aquí se percibe claramente la inseguridad de los Gobiernos informados con respecto a la apreciación y el tratamiento de las pretensiones alemanas; sin haber aún realmente nada concreto sobre el asunto, ya aparecen temores, incertidumbres y reparos al respecto por parte de la OTAN y aun de los Estados Unidos.

Pero el Gobierno alemán no parecía aceptar estos retrasos, a juzgar por la información facilitada por el embajador de la República Federal al ministro español de Asuntos Exteriores. Desde hacía tiempo Alemania venia insistiendo ante la OTAN en que habia que resolver el problema global de las necesidades logísticas de su ejército y, aunque había recibido facilidades en este sentido en otros paises de la Organización Atlántica, detenidos estudios habían puesto de manifiesto que la única posibilidad de hacer frente a esas necesidades se encontraba en España. Así parece habérselo dicho el ministro de Defensa alemán Strauß al general Norstad en Wiesbaden, durante una entrevista celebrada el 27 de enero $^{21}$. Fuera ésta o no la realidad de los hechos, lo cierto es que,

${ }_{19} \mathrm{lbidem}$. De hecho se informó detalladamente en la prensa internacional de la aparición de slogans antisemitas y nazis en Alemania.

20 Traducción del francés del autor del telegrama del 16-1-1960. AMAE, Leg. R-8607, Exp. 6. Aunque no se distinguen ni remitente ni destinatario, se trata probablemente del telegrama que fue enviado desde la OTAN, posiblemente por Norstad, al Gobierno alemán - la embajada alemana en Bruselas.

${ }^{21}$ Así lo describe el documento español. AMAE, Leg. R-8607, Exp. 6. Nota confidencial $\mathrm{NCl}$, núm. 67/60. 
dando impulso a las conversaciones con España, aumentaba considerablemente la presión sobre los Gobiernos informados.

Durante la citada entrevista el comandante en jefe de las fuerzas de la OTAN en Europa había dado su conformidad para que se celebrasen las conversaciones exploratorias entre Alemania y España. En consecuencia, el Gobierno federal, reunido con su Consejo de Defensa, acordó iniciarlas inmediatamente. El embajador de Bonn en Madrid informó al ministro español de Asuntos Exteriores de la inminente llegada de una persona con este fin ${ }^{22}$. El día 15 de febrero no sólo llegó una persona, sino una pequeña comisión, compuesta por un general y dos jefes, quienes se pusieron al habla con una delegación del Alto Estado Mayor dirigida por el general Carmelo Medrano ${ }^{23}$. Los contactos no duraron más de 48 horas. Los alemanes expusieron con detalle los deseos de su Gobierno, mientras la delegación española se limitó a escuchar con atención las proposiciones alemanas. Esto parece haber causado irritación a la comisión alemana, que al parecer esperaba respuestas concretas para avanzar en el curso de la negociación. Funcionarios de la embajada alemana tuvieron que intervenir, dando a considerar a los visitantes los largos procesos de cualquier decisión en cuestiones de política exterior ${ }^{24}$.

En este asunto el Gobierno alemán no podía esperar una decisión rápida por parte española. El proyecto alemán tenía que ser considerado de carácter multilateral, y era por tanto para España un asunto delicado y complejo. El Gobierno español no se quería ver sometido a ninguna presión, y, como comentan documentos españoles, "en este viaje no podian [los alemanes] pedir otra cosa que atención para escucharles» ${ }^{25}$.

La prisa por llegar a un rápido resultado se muestra asimismo en otro incidente que ocurrió momentos antes de salir la comisión alemana para España, cuando Gran Bretaña y Estados Unidos habian realizado una gestión en Bonn pidiendo que se aplazara el viaje, cosa que no atendió el Gobierno alemán ${ }^{26}$.

22 Según informaba el embajador alemán al ministro español de Asuntos Exteriores. AMAE, Leg. R-8607, Exp. 6.

${ }_{23}$ AMAE, Leg. R-8607, Exp. 6. Información confidencial del general jefe del Alto Estado Mayor, Muñoz Grandes, al ministro de Asuntos Exteriores el 18-2-1960.

${ }^{24}$ AMAE, Leg. R-8607, Exp. 6. Nota confidencial NCl, núm. 67/60.

${ }^{25}$ Ibidem.

${ }^{26}$ lbidem. Este incidente y la falta de información por parte alemana al Gobierno español causó serios disgustos al ministro de Asuntos Exteriores español. 


\section{SE PRODUCE EL ESCÁNDALO}

Así estaban las cosas cuando el periodista norteamericano Cyrus Sulzberger publicó en The New York Times un artículo que tuvo una enorme resonancia en la prensa internacional. A él hicieron referencia durante semanas los titulares de los periódicos, poniendo a la República Federal en una situación embarazosa ante la opinión pública mundial en vísperas de la reunión de los Cuatro Grandes en Ginebra ${ }^{27}$. El artículo de Sulzberger contenia datos que no eran correctos, al ir más allá de la realidad de los hechos, pero facilitaba elementos informativos suficientes para deducir que el periodista norteamericano había obtenido su información de fuente fidedigna. ¿Cuál había sido esa fuente? ¿Quién podia estar interesado en provocar el escándalo? ¿Francia? ¿Gran Bretaña? ¿El mismo Spaak?

Comenzaron, pues, las especulaciones sobre quién habría podido informar a Sulzberger con la intención de que se publicaran los planes alemanes para lograr así entorpecer las conversaciones o quizás impedirlas. En un primer momento el Gobierno español sospechó de Spaak, aduciendo como argumento "plausible" el comentario de que él nunca perdonó a Franco el haber estado en una cárcel española en $1940{ }^{28}$. Spaak era, sin duda alguna, junto con los Gobiernos de Noruega y Dinamarca, uno de los principales oponentes a la adhesión de España a la OTAN. Sin embargo, cabe dudar de que el secretario general, por motivos puramente personales, se empeñara en obstaculizar por tal procedimiento las negociaciones previstas entre España y Alemania Occidental.

Naturalmente, la información de Sulzberger podia haber procedido asimismo del State Department o del Foreign Office, al no estar de acuerdo con el rápido desarrollo de las conversaciones hispano-germanas. Presuponiendo una reacción desfavorable en la opinión pública, los Gobiernos norteamericanos e ingleses podían bloquear de esta manera toda negociación, si bien este supuesto se contradice con la postura tomada por el Gobierno norteamericano en el telegrama del 18 de enero.

Otras conjeturas apuntan a que Sulzberger habría obtenido sus informaciones de fuentes francesas. Esto se basa en que Sulzberger vivía entonces en París y era muy partidario de De Gaulle. Así, en la cuestión

\footnotetext{
${ }^{27}$ Véase Sulzberger, Cyrus L., A Foolish Project: West German Negotiations For Facilities in Spain Should Be Canceled. The New York Times, 23-2-1960.

${ }^{28}$ AMAE, Leg. R-8607, Exp. 6. Nota confidencial NCl, núm. 67/60.
} 
de la reestructuración de la OTAN, no sólo había abogado en favor de una solución aceptable para De Gaulle, sino que además fue él quien hizo pública la posición de De Gaulle ${ }^{29}$. Sulzberger poseía por tanto buenas relaciones con el Quai d'Orsay. Estas suposiciones se podrian respaldar alegando que la indiscreción de hacer públicas las proyectadas conversaciones hispano-germanas no iba en contra de España, sino que satisfacia los propósitos franceses de seguir manteniendo a la República Federal bajo control y dependencia francesa, especialmente por lo que se refería al sector militar. La instalación de una base militar al otro lado de los Pirineos por un miembro de la OTAN no era en ningún caso del gusto del Gobierno francés. Ya en 1953, durante las negociaciones entre España y Estados Unidos, había mostrado Francia grandes reparos contra la instalación de bases americanas en la Península Ibérica. Francia habia tenido entonces la sensación de ser burlada y sometida al peligro de que los planes estratégicos de la OTAN operaran en lo sucesivo desde España, perdiendo de esta manera su importancia estratégica ${ }^{30}$.

Realmente había sido Lauris Norstad quien informó a Sulzberger de los propósitos alemanes como nos muestran sus memorias ${ }^{31}$. Norstad acudió al célebre periodista estadounidense para comentarle su descontento con los proyectos alemanes siendo éstos de carácter muy delicado pudiendo tener repercusiones políticas y sicológicas muy graves.

"Larry is very worried about the propaganda and psycological implications. While Germany can cite the special agreement of the United States with Spain as a precedent, it is treating on delicate ground. [...] I told him I was going to write about it and I thought my column might very well raise enough reaction to kill the entire project. He smiled" ${ }^{32}$.

Parece ser que la operación fue montada con toda premeditación e incluso poniendo especial atención en elegir el momento más adecuado para ponerla en marcha. Fuentes españolas aseguran que a Sulzberger le fueron entregados los datos que le sirvieron para su articulo el $\begin{array}{lll}6 & 0 & 7\end{array}$ de febrero -es decir quince días antes de su publicación-, con la ad-

\footnotetext{
${ }^{29}$ Así en un comentario sobre el artículo de Sulzberger de Dr. Otto Leichner publicado por la agencia de noticias dpa, el 8-3-1960.

${ }^{30}$ Véase MARQUina, op. cit., págs. 352 y ss.

${ }^{31}$ SulzBerger, Cyrus L., The Last of the Giants. New York 1970, págs. 644 y ss.

32 Ibidem. Naturalmente no se descarta la posibilidad de que Norstad obrase en acuerdo con los gobiernos de las demás potencias implicadas.
} 
vertencia de que no hiciese uso de ellos hasta se le indicase el momento oportuno ${ }^{33}$. Esto sucedió inmediatamente después de los primeros contactos exploratorios en España. Lo que quiere decir que se esperó a que se produjese algún hecho, por mínimo que fuere, que pudiese mostrar que el proyecto alemán habia pasado del plano especulativo al de las realizaciones.

Sulzberger describe con gran detalle los contactos y las conversaciones habidas hasta el momento entre España y Alemania, con las tres potencias informadas, asi como los motivos del propósito alemán de buscar bases militares en el exterior. Estas informaciones las mezcla Sulzberger con una alusión al significado especial de contactos entre Alemania y la España de Franco, y con el temor de que detrás de esta solicitud de facilidades logísticas se hallara la búsqueda por parte del Gobierno alemán de bases para el lanzamiento de misiles ${ }^{34}$. La cautelosa afirmación de la sospecha de la instalación de bases para el lanzamiento de misiles como objetivo real de las negociaciones hispano-alemanas parece indicar que Sulzberger más bien basa su afirmación en reflexiones personales que en informaciones obtenidas.

Analizando comentarios y documentos del Ministerio de Asuntos Exteriores español, se deduce claramente que Alemania no trató con sus interlocutores españoles la cuestión de la instalación de bases para misiles o el estacionamiento de bombarderos. Nada indica que se iniciaran conversaciones en este sentido. Lo único que cabría pensar es si en la mente de los miembros del Gobierno alemán no estaba la idea de instalar verdaderas bases militares. Pero esta hipótesis no se puede verificar aquí, así como tampoco se puede deducir del artículo de Sulzberger.

De todos modos, el artículo de Sulzberger causó una enorme reacción en contra de los propósitos alemanes. En los días siguientes persis-

${ }^{33}$ Así lo dice el documento español sin precisar más el origen de la afirmación. AMAE, Leg. R-8607, Exp. 6. Nota confidencial, NCI, núm. 67/60.

${ }^{34}$ "The Germans seek special air force and missile training facilities on Spanish soil, together with depots for their logistical support".

En alusión a las conversaciones exploratorias alemanas en Madrid sigue Sulzberger en su artículo:

«Where will such "explorations" lead? To begin with, while Bonn and Madrid carefully talk of German "facilities" in Spain, these would in fact be bases, even if only used for training. And the mere mention of such facilities underscores the original ban - now easedon German possession of guided missiles and bombers. It also reminds the world that under the Paris Treaty West Germany was prohibited from manufacturing certain weapons "in its territory". Spain is neither German territory nor subject to the Allied controls that govern Germany's new arms". Sulzberger, Art. cit. 
tió el escándalo de las pretensiones alemanas en las portadas y los editoriales de los periódicos más importantes en Europa. Amplios artículos de fondo sobre las raíces del problema, así como duras críticas, polémicas violentas y reacciones indignadas cubrieron durante dias las primeras páginas de los diarios. El prestigioso Neue Zürcher Zeitung, por ejemplo, informaba con regularidad en sus tres ediciones diarias sobre el curso de la cuestión. La prensa británica reaccionó con especial violencia ante estos acontecimientos, al paso que se iban conociendo más detalles de las negociaciones entre los Gobiernos de Bonn y Madrid sobre la concesión de privilegios militares para tropas alemanas en España. En general comenzó a surgir miedo ante un nuevo e incontrolable fortalecimiento militar de Alemania en torno a un Eje Bonn-Madrid. Aunque era manifiesto que las informaciones y los detalles que se iban conociendo sobre los propósitos de Bonn, se contradecian fuertemente y parecian en gran parte exagerados, la sola afirmación de que Alemania estaba marcando una política militar propia sin consultar a los aliados en la OTAN causó violentas protestas. Cuantos más detalles aparecían durante estos primeros días sobre las supuestas negociaciones hispano-alemanas, más reacciones en contra surgían.

La Unión Soviética aprovechó esta situación de conmoción general para fines propagandisticos contra Alemania y España. En la prensa soviética y en la germano-oriental aparecieron duros ataques contra el militarismo y el revanchismo del Gobierno de Bonn. Además, el Gobierno de la URSS protestó oficialmente contra "la creación de una colaboración militar con la España de Franco", entregando el 4 de marzo una nota de protesta al embajador alemán en Moscú ${ }^{35}$.

El partido socialdemócrata alemán, como partido de la oposición, aprovechó también la situación para atacar la política del Gobierno de Adenauer respecto a España, y solicitó una moción parlamentaria en la Cámara Baja contra las relaciones del Gobierno con España, pais que "pisotea los derechos humanos y es enemigo de la democracia" ${ }^{36}$.

A medida que las protestas se iban incrementando, surgieron también diferentes acusaciones sobre múltiples proyectos alemanes de instalar bases militares en Grecia, África oriental o Irlanda, apareciendo in-

${ }^{35}$ Esta nota fue publicada por la agencia de noticias TASS, el dia 5-3-1960

${ }^{36}$ Deutscher Bundestag, 108. Sitzung. Bonn, den 6. April 1960. Große Anfrage der Fraktion der SPD betr. deutsch-spanische Beziehungen (Drucksache 1663), págs. 58905915. 
cluso denuncias sobre la preparación de bases atómicas en Suiza y la producción de armas nucleares en Bilbao ${ }^{37}$.

Al escándalo producido por Sulzberger siguieron las primeras reacciones por parte oficial respecto de las acusaciones contenidas en el artículo del New York Times. Las primeras declaraciones fueron poco precisas y esclarecedoras. Al parecer la sorpresa por parte de los paises implicados en el asunto habia sido de tal magnitud, lo cual posiblemente secundó en una inseguridad sobre la reacción adecuada. Desmentidos, confirmaciones parciales y datos contradictorios se sucedieron sin interrupción, reflejando claramente esta primera inseguridad.

El día 24 de febrero, Lauris Norstad, general en jefe de las tropas de la OTAN en Europa, se negó a responder en Copenhague a preguntas sobre los supuestos proyectos del Gobierno alemán. Asimismo, declinó todo comentario sobre si había estado informado de los planes alemanes $^{38}$.

Un día más tarde, cuando ya los Gobiernos implicados habian podido aclarar la situación, Norstad no se mostró tan cauteloso y declaró a su llegada al aeropuerto de Fornebu cerca de Oslo:

"Yo comprendo que esto haya despertado una gran sensación, según se aprecia por la prensa. [...] Para nosotros en el cuartel general de la OTAN están perfectamente claros los problemas que Alemania Occidental tiene en este sentido, y comprendemos que deseen tener bases de aprovisionamiento en España, y cualquier otra clase de colaboración militar. Si las conversaciones preliminares entre Alemania y España nos llevase a algo concreto, estoy completamente seguro de que las negociaciones se harian a través y bajo el control del mando de la OTAN" ${ }^{39}$.

Durante los días siguientes se fue aclarando cada vez más la situación, y los hechos ocurridos iban adquiriendo perfiles definidos.

${ }^{37}$ La acusación de la producción de armas atómicas en Bilbao fue presentada por el diputado laborista Edwards en el parlamento inglés. Parliamentary Debates (Hansard), House of Commons, Thursday 25th February, 1960, Volume 618, núm. 64, col., 588 y sig.

${ }^{38}$ Así la noticia de la agencia Reuter, de 25-2-1960.

${ }^{39}$ Declaraciones del general Norstad durante su visita del cuartel general de la OTAN, Koslas, 25 de febrero. Aftenposten, 26-2-1960. Traducción de la Oficina Diplomática de Información. 
El 27 de febrero se pronunció el canciller alemán Adenauer sobre la tan traída y llevada discusión a propósito de las negociaciones de Alemania con el Gobierno español; declaró con palabras persuasivas, que su Gobierno sólo actuaría dentro de la máxima conformidad con los países aliados miembros de la OTAN. Así lo había mantenido hasta aquel momento, y asi lo seguiría manteniendo. Adenauer añadió que habia propuesto con anterioridad en todas las conferencias de la OTAN, de manera oral y por escrito, integrar en su totalidad los abastecimientos y el aprovisionamiento de las tropas - hasta entonces de competencia nacional-, dentro del sistema conjunto de la OTAN. Mientras estas propuestas alemanas continuaran sin ser aceptadas, este asunto seguiría siendo de responsabilidad nacional. Adenauer anunció que el Gobierno de la República Federal solicitaría de nuevo de las autoridades responsables de la Alianza, proveer al ejército alemán de posibilidades para poder responder a las exigencias de la OTAN en la cuestión del aprovisionamiento. Adenauer concluyó subrayando que la seguridad exterior de la República Federal se basaba en secundar decididamente por medio de su gobierno la política de la OTAN ${ }^{40}$.

Con las declaraciones que se sucedían por aquellos días, iba perdiendo fuerza el temor general de que Alemania pudiera intentar poner pie en España por iniciativa propia, sin previa consulta con la OTAN, quedando así desmentidas las preocupaciones de los aliados. Por su parte el general Norstad declaró el 2 de marzo en París, que en este asunto había habido un fondo de hechos reales, una considerable mezcla de ficción y una tremenda carga de emoción ${ }^{41}$.

\section{EL DESENLACE DEL ASUNTO}

Una vez que la opinión pública se había mostrado tan sensible al proyecto alemán, el Gobierno de la República Federal se vio seriamente dificultado para seguir adelante con su propósito. La OTAN había anunciado reiteradamente que los alemanes podían instalar libremente bases logísticas en España, aunque siempre añadieron a continuación que sería deseable que el Gobierno alemán sondeara las posibilidades de estable-

${ }^{40}$ Declaraciones del canciller Adenauer del 27 de febrero en Newe Zürcher Zeitung. 29-2-1960.

${ }^{41}$ Declaraciones hechas al corresponsal en París del diario The Daily Telegraph. 
cer dichas bases en los países miembros de la OTAN. De esta manera ya quedaba marcado el camino que seguiría el asunto, siendo ahora obligación de los paises del Tratado Atlántico hacer concesiones al Gobierno de Bonn y presentar propuestas para aliviar una situación tan incómoda para la misma Alianza. Bajo estas premisas tuvo lugar en París el 1 de abril una reunión de los ministros de Defensa de los países miembros de la Alianza Atlántica. Aquí se presentaron diversos planteamientos y se ofrecieron diferentes posibilidades para dar solución al problema. Por un lado fuentes diplomáticas comentaban que el Gobierno británico insistiria en que las reservas de aprovisionamiento para el caso de una posible guerra en Europa se redujeran en sólo 30 dias, en lugar de los 90 que entonces estaban previstos. De esta manera no necesitarían las fuerzas alemanas ningún tipo de bases adicionales, bastándoles las existentes dentro de la OTAN ${ }^{42}$.

Pero no por esto podrían evitar los paises aliados, especialmente Francia y Gran Bretaña, tener que hacer concesiones y ofrecer al Gobierno alemán instalaciones propias en sus respectivos territorios.

La búsqueda de estas facilidades logísticas seguía presentándose difícil. Las conversaciones comenzadas al respecto con diferentes países miembros de la Organización Atlántica se enfrentaron con diferentes problemas. Noruega y Dinamarca, debido a su posición estratégica, no podian ser tenidos en cuenta para dar salida a las peticiones alemanas, y lo mismo ocurría con los Países Bajos y Bélgica, dada la escasa extensión de sus territorios. Por esto todos los esfuerzos se concentraron sobre Francia y Gran Bretaña, aunque también en este último país era escaso el espacio disponible dadas las amplias facilidades ya concedidas al Mando Aéreo Estratégico de Estados Unidos ${ }^{43}$.

Por si esto fuera poco, en los diferentes paises implicados existían serios inconvenientes de política interior para permitir el estacionamiento de tropas alemanas en su territorio. La presencia de uniformes alemanes despertaría en los distintos países los malos recuerdos de la Segunda Guerra Mundial y causaría violentas reacciones en la opinión pública. El miedo ante problemas políticos de esta índole dificultó de forma considerable la rápida solución del caso, aunque podria decirse que el conocimiento del problema difundido merced al artículo de Sulzberger habia ayudado indirectamente a los gobiernos a preparar la propia opinión pú-

42 AMAE, Leg. R-8607, Exp. 6. Telegrama confidencial del embajador español en Londres al ministro de Asuntos Exteriores, 31 de marzo.

${ }^{43}$ AMAE, Leg. R-5846, Exp. 1. Nota informativa, Madrid, 7-12-1960. 
blica en los respectivos paises sobre concesiones que habría que hacer al ejército alemán. De hecho, al llegarse a un acuerdo con Alemania en este asunto, la opinión pública no reaccionó de una forma especialmente negativa.

Las conversaciones del Gobierno alemán con España no se vieron en un principio demasiado afectadas por los incidentes de febrero. Incluso la presentación de la moción parlamentaria en el «Bundestag" por el partido de la oposición no parecia haber obstaculizado adicionalmente la evolución de los contactos. Los objetivos del Gobierno de Bonn no parecian haber cambiado.

El encargado de Negocios de la embajada alemana en Madrid, Dr. Werz, comunicó de parte de su Gobierno, que éste mantenia la misma posición que anteriormente respecto a todo el problema logístico de la OTAN en relación con España. Su deseo seguía siendo el de continuar las conversaciones iniciadas. En todo caso, las negociaciones formales con España no tendrian lugar hasta después de haberse discutido en el seno de la OTAN el problema logístico general, suscitado por Alemania, y de haber obtenido la autorización de la propia OTAN para abrir tales negociaciones ${ }^{44}$.

El Gobierno alemán prosiguió por tanto ahora el asunto por dos vías simultáneamente. Su propósito primordial era llegar a imponer sus propuestas dentro de la OTAN. La alternativa, y al mismo tiempo un medio de presión sobre los organismos de la Alianza Atlántica, eran las conversaciones con España. De esta forma siguieron las negociaciones alemanas con la OTAN para resolver sus necesidades logísticas, mientras gravitaba sobre la Organización el peso de llegar a un acuerdo con Alemania Occidental para impedir que Bonn siguiera un camino propio, sin poder ser controlada y sin que la Organización pudiera influir en la futura evolución del problema. Precisamente esto es lo que tenía que ser evitado por los países miembros de la OTAN.

A primeros de octubre se llegó finalmente en París a un acuerdo por el que se concedió al ejército alemán disponer en Francia de terreno de entrenamiento y de depósitos de suministros militares. En virtud del mismo acuerdo se permitía a las fuerzas militares alemanas mantener temporalmente unidades militares en territorio francés, así como el uso de zonas de entrenamiento francesas. Francia permitiria además el uso de

${ }^{44}$ Asi el Dr. Werz en una gestión personal ante el Ministerio de Asuntos Exteriores de Madrid, el 22-3-1960. AMAE, Leg. R-8607, Exp. 6. Nota confidencial NCl, núm. 67/60. 
depósitos de almacenamiento y permitiría el libre movimiento entre estos últimos y Alemania Occidental. Los depósitos permanecerían bajo mando, administración y guarnición franceses, permitiéndose el uso sin restrinciones de tales depósitos por el ejército alemán ${ }^{45}$.

Gracias a las facilidades conseguidas con este acuerdo se preveia que de los depósitos de aprovisionamiento necesarios para 90 días de combate, que la OTAN seguia imponiendo a la República Federal como a los demás miembros de la Alianza, los correspondientes a 15 días estarían en territorio alemán, mientras que los restantes 75 , en territorio francés. Como distintivo deberian llevar los soldados alemanes en los campos franceses, en consideración de la población francesa, un uniforme de color kaki y no el verde, que seria relacionado con la "Wehrmacht" y traeria el recuerdo de la ocupación alemana ${ }^{46}$.

También en Londres encontró Alemania Occidental ahora más comprensión. Con la ampliación del estatuto sobre las tropas de los paises miembros de la OTAN en territorio de Gran Bretaña en julio del mismo año - que incluía ahora a la República Federal- se creó el marco jurídico para que el ejército alemán, equiparado al de los demás miembros de la OTAN, pudiera utilizar bases militares inglesas ${ }^{47}$.

Así se logró finalmente que la instalación de bases alemanas en España resultara innecesaria.

\section{CONCLUSIONES}

De esta suerte se llegó al término del problema en torno a la instalación de bases de aprovisionamiento por parte del Gobierno alemán en el exterior, problema que apenas habia surgido cuando adquirió ya di-

45 AMAE, Leg. R-5845, Exp. 32. Carta del embajador español en París al ministro de Asuntos Exteriores, 27-10-1960.

${ }_{46}$ AMAE, Leg. R-5846, Exp. 1. Nota informativa, Madrid, 7-12-1960. AMAE, Leg. R5845, Exp. 32. Carta del embajador español en Paris al ministro de Asuntos Exteriores, 27. 10-1960.

${ }^{47}$ Exchange of Notes between the Government of the United Kingdom of Great Britain and Nothern Ireland and the Government of the Federal Republic of Germany applying to any force of the Federal Republic serving in the United Kingdom the provisions of the Agreement between the Parties to the North Atlantic Treaty Organisation regarding the Status of their Forces, signed at London on June 19, 1951. Bonn, july 12, 1961. Treaty Series, núm. 102 (1961). 
mensiones de singular relieve, sin faltar en momentos un notable dramatismo. Aunque otros países miembros de la OTAN habían concluido, o se hallaban negociando acuerdos militares con España, al comenzar Adenauer conversaciones con este país sobre un asunto tan delicado, tuvo que haber sido consciente de la polémica que ello suscitaria tan pronto como se llegase a conocimiento de la opinión pública internacional. Las relaciones hispano-alemanas seguian siendo un tema especialmente delicado y el control de las fuerzas armadas alemanas a través de la OTAN había sido y seguía siendo, en especial para Francia, un factor en su política exterior.

Aceptar el establecimiento de bases militares alemanas en España, pais no controlable por la Alianza Occidental, iba más allá de lo que la OTAN podia conceder a Alemania, pese a que la imagen de este país en el extranjero había mejorado considerablemente.

En todo caso el ejército alemán necesitaba bases de aprovisionamiento en el exterior. Esto habia sido reiteradamente puesto de relieve por fuentes oficiales de la OTAN. Ni las conversaciones mantenidas con Francia, ni al parecer la experiencia de las maniobras militares de la OTAN "Side Step", habían servido para alcanzar los resultados deseados por el Gobierno alemán. Por aquellas fechas se produjo la visita del ministro español de Asuntos Exteriores a Bonn. ¿Por qué no aprovechar esta visita para intentar solucionar el problema en España? La posición de España en el exterior había mejorado hasta tal punto que corrian rumores sobre una posible adhesión de este país al Tratado del Atlántico Norte. Además, existian buenas relaciones personales con el Gobierno español. Por tanto, nada podía ser más deseable por parte alemana que la instalación de bases militares en el país ibérico, dada ante todo su excelente ubicación estratégica.

Aparte de todos estos argumentos existían otros de peso posiblemente decisivo en el tema. Si las peticiones alemanas de bases eran reconocidas por los organismos de la OTAN; si la República Federal era un país soberano y en un principio libre para poder buscar contactos políticos e incluso militares donde quisiera; si España podía ser tenida seriamente en consideración al respecto; siendo previsible que la búsqueda de estas facilidades en España no sería del agrado de sus aliados y les causaría serias dificultades, precisamente por todo esto disponía Adenauer, al comenzar las conversaciones con España, de una fuerte baza política para fortalecer la posición alemana dentro del Consejo de la OTAN y poder dar un impulso decisivo a su propuesta sobre la integración del sistema de abastecimientos, marginando las prevenciones aún existentes contra las fuerzas armadas alemanas. 
Adenauer alcanzó estos objetivos. El convenio sobre las tropas nacionales de la OTAN del año 1951 fue ampliado a la República Federal; de repente le fue ofrecido a Alemania Occidental el acceso a bases militares en Cognac, no ya en Argelia. Incluso el deseo alemán de una mayor integración entre los ejércitos nacionales de los países miembros de la OTAN, y con ello el fortalecimiento de la estructura supranacional, se vio realizado al ser discutido en el seno de la Unión Occidental Europea y aceptado allí unánimemente ${ }^{48}$. La "variante» española se hizo definitivamente innecesaria.

${ }^{48}$ Assembly of Western European Union. Report submitted on behalf of the Committee on Defense Questions and Armaments by Mr. Goedhard, Rapporteur. Document 180, 25th october, 1960. 